\title{
Translational Suppression of Calpain Blocks Long-term Potentiation
}

\author{
Peter Vanderklish, ${ }^{1}$ Eric Bednarski, and Gary Lynch
}

Center for the Neurobiology of Learning and Memory

University of California at Irvine

Irvine, California 92717

\begin{abstract}
Transfection with antisense oligonucleotides was used to reduce calpain 1 activity to $\sim 50 \%$ of normal values in cultured hippocampal slices. This had no detectable effects on baseline synaptic responses but greatly reduced the incidence and magnitude of long-term potentiation induced with a $\theta$-burst stimulation paradigm. These results suggest that activation of calpain by repetitive bursts of afferent activity, as shown to occur in prior studies, is an essential step in the production of stable increases in synaptic strength.
\end{abstract}

\section{Introduction}

Calpain 1, a neutral cysteine protease activated by low micromolar concentrations of calcium, is found in neurons at sites throughout the mammalian brain (Siman et al. 1985; Fukuda et al. 1990; Perlmutter et al. 1990). Recent studies provided two lines of evidence that the enzyme plays an important role in long-term potentiation (LTP), a calcium-triggered form of synaptic plasticity that is induced rapidly, extremely stable, and regarded as a potential substrate of memory (Bliss and Lomo 1973; for review, see Teyler and DiScenna 1984; Lynch et al. 1991a,b; Bliss and Collingridge 1993). First, patterns of afferent stimulation used to induce LTP cause a marked accumulation in target dendrites of a proteolytic fragment known to be generated by calpain (Vanderklish et al. 1995). Earlier work had shown that repetitive stimulation elevates calcium into the range needed for calpain activation (Guthrie et al. 1991; Muller and Connor

${ }^{1}$ Corresponding author.
1991 ) and that calpain, together with the parent protein of the breakdown product (brain spectrin), is present in fine dendritic processes (Carlin et al. 1983; Ivy et al. 1988; Fukuda et al. 1990; Perlmutter et al. 1990). Second, LTP is more readily induced in mice with abnormally low levels of calpastatin, an endogenous inhibitor of calpain, than is the case for control animals (Muller et al. 1995); thus, a condition expected to promote calpain activation facilitates the production of LTP.

Critical to the argument for calpain's involvement in LTP is the issue of whether reductions of its activity prevent the development and/or stabilization of the potentiation effect. Drugs that inhibit calpain block LTP both in vitro (del Cerro et al. 1990; Denny et al. 1990) and in vivo (Staubli et al. 1988), but it is unclear if this reflects suppression of the protease itself or related enzymes. Translational suppression can be used to selectively reduce the concentration of individual proteins from cultured brain slices (Vanderklish et al. 1992; Bednarski et al. 1995). Here we report that suppression of calpain 1 with this method substantially reduces the capacity of hippocampal synapses to express stable LTP.

\section{Materials and Methods}

PREPARATION OF ORGANOTYPIC CULTURES OF HIPPOCAMPUS

Hippocampal slices were prepared from 10- to 12-day-old rats using conventional techniques, placed on membranes, and incubated at the interface of a static bath and a $5 \% \mathrm{CO}_{2}$ humidified atmosphere. Under sterile conditions, brains were rapidly dissected and transverse sections ( 400 $\mu \mathrm{m})$ were cut from the middle approximately two-thirds of both hippocampi; 18-24 slices were collected from each animal and randomly distrib-

LEARNING \& MEMORY 3:209-217 (c) 1996 by Cold Spring Harbor Laboratory Press ISSN1072-0502/96 \$5.00

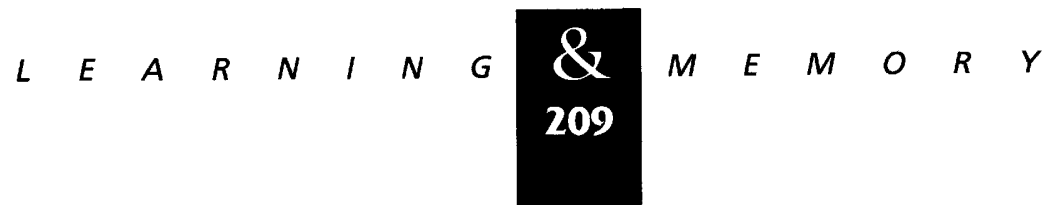


uted among the inserts (30-mm Millipore-CM) of preequilibrated six-well culture plates. To facilitate within-animal comparisons, each culture plate contained slices from one animal only. The hippocampus was dissected (and slices collected) in an iced buffer composed of $124 \mathrm{~mm} \mathrm{NaCl}, 3 \mathrm{~mm}$ $\mathrm{KCl}, 1.25 \mathrm{~mm} \mathrm{NaH}_{2} \mathrm{PO}_{4}, 4 \mathrm{~mm} \mathrm{MgSO}_{4}, 2 \mathrm{~mm} \mathrm{CaCl}_{2}$, $25 \mathrm{~mm} \mathrm{NaHCO}_{3}, 5 \mathrm{~mm}$ HEPES, $20 \mathrm{~mm}$ D-glucose, $0.5 \mathrm{~mm}$ ascorbate, $100 \mu \mathrm{M}$ adenosine, $5 \mathrm{U} / \mathrm{ml}$ of penicillin ( $\mathrm{pH}$ 7.25). Once explanted, cultures were maintained in a humidified FORMA incubator $\left(5 \% \mathrm{CO}_{2} ; 36-37^{\circ} \mathrm{C}\right)$ and fed every other day with $1 \mathrm{ml} /$ well of culture media: $75 \%$ MEM/ Hank's salts (1:1) and 25\% horse serum (heattreated at $56^{\circ} \mathrm{C}$ for $1 \mathrm{hr}$ ), with $5 \mathrm{~mm} \mathrm{NaHCO}_{3}, 3$ mM glutamine, $30 \mathrm{~mm}$ D-glucose, 25 mм HEPES, $2.5 \mathrm{mM} \mathrm{MgSO}_{4}, 2 \mathrm{~mm} \mathrm{CaCl}_{2}, 0.5 \mathrm{~mm}$ ascorbate, 1 $\mathrm{mg} /$ liter of insulin $(\mathrm{pH} 7.2)$ at $37^{\circ} \mathrm{C}(0.2 \mu \mathrm{m}$ sterile filtered). Translational suppression was begun after 10 days in vitro by adding the oligonucleotides to the culture media. Sense and antisense treatment conditions were included in each culture plate.

TRANSLATIONAL SUPPRESSION OF CALPAIN 1 WITH ANTISENSE OLIGONUCLEOTIDES

After 10 days in vitro, the explants were exposed to antisense, $5^{\prime}$-GGTCGGGCTCCGAGTAGCGGG-3', or sense, 5'-CCCGCTACTCGGAGCCCGACC-3', oligonucleotides corresponding to a 21 base stretch in the published $3^{\prime}$ coding sequences of human and rabbit calpain 1 that exhibits $100 \%$ homology between the two species (Aoki et al. 1986; Emori et al. 1986). The target region selected (bases 746-766 according to the numbering system for the rabbit sequence) is only $57 \%$ homologous to calpain 2 , an isoform requiring millimolar calcium for activation, and has a low prob. ability of forming a hairpin loop structure. The oligonucleotides were applied at a concentration of $25-30 \mu \mathrm{g} / \mathrm{ml}$ in culture media and replenished daily by exchanging the media with a fresh dilution of the probes. This process was repeated for 5 consecutive days.

\section{ELECTROPHYSIOLOGY}

At the conclusion of the 5-day transfection period, slices were transferred to an interface recording chamber and tested for the ability to express
LTP; at the time of testing, the experimenter was not aware of the treatment group the slices belonged to. Quarter- to half-maximal field EPSPs were elicited in the apical dendrites of the CA1 region by single pulse $(0.1 \mathrm{~Hz})$ stimulation of the Schaffer collateral fibers. Two populations of these projections were independently stimulated in each slice with twisted tungsten bipolar stimulation electrodes positioned on either side of a pulled-glass microrecording electrode in stratum radiatum (i.e., one arranged in the orthodromic position and one in the antidromic). This was done to assess whether high-frequency stimulation along one path had lasting heterosynaptic effects along another path-a test that helps to qualify potentiation as LTP. Strict tests of the independence of the pathways (i.e., the degree to which the synaptic populations overlap) such as summation of EPSPs or evidence of presynaptic facilitation across paths, were not conducted for all slices. If baseline responses were stable for at least $10 \mathrm{~min}$, then attempts were made to induce LTP by applying $\theta$-burst stimulation (four pulses at $\mathbf{1 0 0}$ $\mathrm{Hz}$ with $200 \mathrm{msec}$ between bursts) to one of the two electrodes. [The $\theta$-burst stimulation paradigm mimicks endogenous neuronal spiking patterns in hippocampus during learning, efficiently recruits NMDA receptor-mediated synaptic currents, and can produce saturative LTP with modest levels of stimulus duration and intensity (Larson and Lynch 1986).] To maximize the degree of facilitation across bursts and to avoid triggering epileptiform activity, $\theta$-bursts were applied in pairs separated by $10-15 \mathrm{sec}$.; six to seven pairs were given per stimulus train, during which the stimulus duration was increased from 0.10 to $0.12 \mathrm{msec}$. Responses to single pulses were then monitored for an additional $30-40 \mathrm{~min}$. This testing process was repeated for all of the slices explanted to a particular well (typically three to four) that met physiological criteria: those slices demonstrating pairedpulse facilitation (interpulse interval $=85 \mathrm{msec}$ ) and maximum dendritic field EPSPs of at least -2 $\mathrm{mV}$. The slices were then harvested for biochemical analyses.

\section{ACTIVITY ASSAY AND WESTERN BLOT DETERMINATIONS OF RELATIVE CALPAIN LEVELS}

The efficiency of translational suppression at reducing calpain 1 levels was estimated primarily by activity assays. Immunoblot procedures had 
proven to be unreliable in previous studies (Bednarski et al. 1995), a problem that likely stems from the potentially low reactivity of the antibodies used with tissue-specific isoforms of the protease (Saido et al. 1994). Partial purification of calpain 1 provided a means to quantify $\mathrm{Ca}^{2+}$-dependent proteolysis in the hippocampal explants (Peterson et al. 1991) in terms of relative ${ }^{14} \mathrm{C}$ caseinolytic activity. Per six-well culture plate, sense- and antisense-treated slices were gathered into separate pools, pelleted, and subjected to hy. potonic lysis by tip sonication (Virsonic model 16850 ) in 10 volumes of $5 \mathrm{~mm}$ Tris, 2 mm EGTA ( $\mathrm{pH}$ 7.4 ), with one freeze-thaw cycle. The resulting lysates were brought to equivalent protein concentrations (Bradford 1976) with lysis buffer, then centrifuged. The supernatants were saved, and the pellets were then washed with an equal volume of the same buffer including $300 \mathrm{~mm} \mathrm{KCl}$; the supernatants from this wash were combined with those from the original lysis. The samples were then diluted to $50 \mathrm{~mm} \mathrm{KCl}$ with $20 \mathrm{~mm}$ Tris, $1 \mathrm{mM}$ EGTA, $0.02 \% \mathrm{NaN}_{3}(\mathrm{pH} 7.4)$ and added to $1 \mathrm{ml}$ of DEAE Biogel-A slurry. Proteins were allowed to adsorb for $1 \mathrm{hr}$ with occasional vortexing before loading the DEAE into a $1-\mathrm{cm}$ diameter column in excess DEAE buffer ( $20 \mathrm{~mm}$ Tris, $50 \mathrm{~mm} \mathrm{KCl}, 1 \mathrm{~mm}$ EGTA, $0.02 \% \mathrm{NaN}_{3}$ at $\mathrm{pH} 7.4$ ). DEAE was allowed to gravity pack; then the flowthrough was cycled through the column twice and saved. After washing with DEAE buffer, calpain was eluted by step gradient with $300 \mathrm{~mm} \mathrm{KCl}$ in DEAE buffer. The eluate was brought to an ionic strength of $500 \mathrm{~mm}$ with $\mathrm{NaCl}$ and allowed to equilibrate for at least $30 \mathrm{~min}$. The calpain-enriched DEAE fractions were then loaded onto $1.5-\mathrm{ml}$ phenyl-Sepharose columns over five cycles; the columns were washed with $5 \mathrm{ml}$ of DEAE buffer containing $350 \mathrm{~mm} \mathrm{NaCl}$ in place of $\mathrm{KCl}$. Calpain and remaining proteins were eluted with two volumes of DEAE buffer lacking $\mathrm{NaCl}$ and $\mathrm{KCl}$, followed by one volume of $20 \%$ ethylene glycol in DEAE buffer. The resultant fractions were concentrated using centricon-30 filtration units (Amicon) and the final protein content was then determined by Bradford assay. All steps were carried out at $4^{\circ} \mathrm{C}$.

Calcium-dependent proteolysis in antisense and sense concentrates was quantified as the amount of TCA-soluble radioactivity yielded in duplicate incubations $\left(35^{\circ} \mathrm{C}\right.$ for $\left.12 \mathrm{~min}\right)$ of the following: $50 \mu \mathrm{l}$ of sample (equalized for protein between samples before or after fractionation), $60,000 \mathrm{cpm}{ }^{14} \mathrm{C}$-casein, $25 \mathrm{~mm} \beta$-mercaptoetha- nol, with either $10 \mu \mathrm{M}$ free $\mathrm{Ca}^{2+}$ or $5 \mathrm{~mm}$ EGTA. The net $\mathrm{Ca}^{2+}$-stimulated activity was compared between pools of sense and antisense cultures from a common culture plate; this activity was typically $\sim 70$-fold that of slice homogenates and was completely inhibited by $200 \mu \mathrm{M}$ calpain inhibitor 1. These procedures have been employed elsewhere to measure the relative levels of calpain activity in cultured slices (Bednarski et al. 1995).

The efficiency of translational suppression of calpain 1 also was assessed by measuring on immunoblots the relative amounts of a calpain-generated spectrin breakdown product in antisenseand sense-treated slices challenged with $200 \mu \mathrm{M}$ NMDA for $20 \mathrm{~min}$. Following incubation with the excitotoxin, slices were collected on ice in a buffer composed of $20 \mathrm{mM}$ HEPES, $0.3 \mathrm{M}$ sucrose, 2 mM EDTA, 2 mм EGTA, $100 \mu \mathrm{m}$ leupeptin, and 20 $\mu \mathrm{g} / \mathrm{ml}$ of TPCK ( $\mathrm{pH} 7.4$ ), then homogenized by tip sonication. The protein concentrations of the homogenates were determined by Bradford assay, and aliquots of the homogenates were boiled for 5 min with one-third volume of $3 \times$ concentrated sample buffer ( $150 \mathrm{~mm}$ Tris, 30\% glycerol, 6\% SDS, $3.75 \mathrm{~mm}$ EDTA, $3 \% \beta$-mercaptoethanol at $\mathrm{pH}$ 6.8). Boiled samples were brought to the same protein concentration with dilute sample buffer, after which $60 \mu \mathrm{g}$ of protein from each sample (30 $\mu \mathrm{l})$ was subjected to SDS-PAGE over a $3 \%-17 \%$ linear gradient of acrylamide/bisacrylamide (37.5: 1) with a $4 \%$ stacking gel. Resolved proteins were transferred to nitrocellulose sheets $(0.2 \mu \mathrm{m}$ pore size) in a Bio-Rad Transblot cell over a 12- to 15-hr period at $30 \mathrm{~V}$.

Immunodetection of proteolytic fragments of spectrin utilized antibodies raised to the five amino-terminal amino acids (GMMPR) of the 150$\mathrm{kD}$ carboxy-terminal breakdown product generated by calpain (Saido et al. 1993; Bahr et al. 1995). This spectrin epitope is produced exclusively by calpain cleavage and not by other mammalian proteases tested (Roberts-Lewis et al. 1994) and thus serves as a reliable index of calpain activation in situ. After transfer, nitrocellulose sheets were washed in Tris-buffered saline (TBS; $25 \mathrm{~mm}$ Tris, $250 \mathrm{~mm} \mathrm{NaCl}$ at $\mathrm{pH} \mathrm{7.4),} \mathrm{blocked} \mathrm{for}$ $1 \mathrm{hr}$ with $5 \%$ (wt/vol) nonfat dry milk dissolved in TBS, then washed $2 \times 10 \mathrm{~min}$ in TBS containing $0.1 \%$ Tween 20 (TTBS). Primary antibody was diluted in TTBS containing $1.5 \%$ nonfat dry milk and incubated with the blots overnight. Following two 10-min washes in TTBS, alkaline phosphatase-coupled goat antirabbit secondary antibody (Bio- 
Vanderklish et al.

Rad) was applied to the blots at a dilution of 1 : 2200 in $1.5 \% \mathrm{milk} / \mathrm{TTBS}$ for $1-2 \mathrm{hr}$. Procedures for color development using the 5-bromochloro3-indolyl phosphate/nitroblue tetrazolium alkaline phosphatase substrate system were as recommended by Bio-Rad. Densitometric quantification of immunolabeled spectrin breakdown products was performed on a computerized video image analysis system, and values [(mean optical density - background $) \times$ (image area)] were compared for antisense and sense samples within the same blots. Some of the immunoblots were counterstained with antibodies specific for synaptophysin (Boehringer Mannheim), cathepsin D (Chemicon), or glutamate receptor 1 (M. Hennegriff, A. Arai, M. Kessler, P. Vanderklish, M.S. Mutneha, G. Rogers, R.L. Neve, and G. Lynch, in prep.) according to similar methods.

\section{Results}

In assays using ${ }^{14} \mathrm{C}$-casein as a substrate, it was found that 5 days of oligomer exposure re- duced the amount of caseinolytic activity stimulated by $10 \mu \mathrm{M}$ calcium by $\sim 50 \%$ in extracts of antisense slices relative to paired sense controls. Figure 1A shows the average percent reduction observed in two sets of slices that were tested for LTP and the average measured when slices treated identically, but not tested, were included. The level of suppression of ${ }^{14} \mathrm{C}$-caseinolytic activity achieved is very close to that obtained in a previous study that utilized the same transfection procedures (Bednarski et al. 1995). The efficiency of calpain 1 suppression was also gauged by quantifying excitotoxin-induced proteolysis of the endogenous cytoskeletal substrate brain spectrin (fodrin). Antibodies selective for a spectrin epitope generated by calpain (but not by other mammalian proteases tested) were used to detect the cleavage fragment on Western blots (Fig. 1B). Stimulation of slices with NMDA ( $200 \mu \mathrm{M}$ for $20 \mathrm{~min}$ ), a manipulation known to induce extensive calpain activation in situ, produced significantly lower amounts of the spectrin breakdown product in an-

Figure 1: Selective suppression of calpain 1 activity with antisense oligonucleotides. After 10 days in vitro, hippocampal slice cultures were exposed to either of the following 21 -mer oligonucleotides at a concentration of $25-30 \mu \mathrm{g} / \mathrm{ml}$ for 5 days: Antisense, 5'-GGTCGGGCTCCGAGTAGCGGG-3'; sense, 5'-CCCGCTACTCGGAGCCCGACC-3'. To allow within-animal comparisons, the two treatments were carried out on slices explanted from the same animal to neighboring inserts in a six-well culture plate.
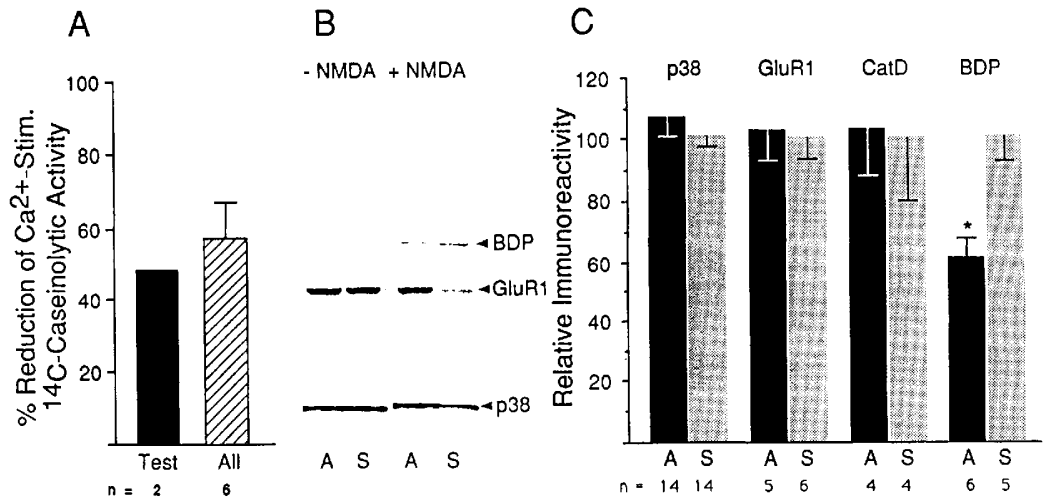
(A) Bar graph illustrating the mean percent reduction in $\mathrm{Ca}^{2+}$-stimulated caseinolytic activity in antisense- relative to sense-treated cultures. After physiological testing, slices of a common plate were pooled by treatment group, then fractionated after equilibration of protein contents. Addition of $10 \mu \mathrm{M}$ free $\mathrm{Ca}^{2+}$ to the calpain 1 -enriched fractions resulted in an average twofold greater proteolytic activity toward exogenous ${ }^{14} \mathrm{C}$-casein in sense relative to antisense extracts. Data obtained from cultures tested (Test) for LTP and including cultures treated identically but not tested (AlI) are represented. Experiments in which protein content was equilibrated after partial purification gave similar results (not shown). (B) Immunoblot demonstrating the effect of translational suppression of calpain 1 on the concentrations of pre- and postsynaptic markers and on a proteolytic breakdown product (BDP) derived through the action of calpain 1 on endogenous spectrin. Cultured slices were challenged with 200 $\mu M$ NMDA for 20 min then harvested and processed in parallel with controls for immunoblot analyses in which the levels of GluR1, p38, and BDP were determined for each sample. Samples from antisense (A) and sense (S) cultures exhibited roughly equal amounts of staining for GluR1 and p38 under control conditions ( - NMDA); the spectrin BDP was not detected in these samples. The spectrin BDP was detected in samples from NMDA-treated cultures (+NMDA) but was present to a lessor degree in antisense samples. Calpain 1 suppression also attenuated the degredation of GluR1, as evidenced by the relative levels of the 100-kD antigen in NMDA-treated cultures; synaptophysin remained unchanged. (C) Group data for normalized levels of the above three proteins and cathepsin D (Cat D). A statistically significant difference was found in the amount of spectrin BDP induced with NMDA in antisense as compared with sense cultures: $61.17 \pm 7.06$ vs. $100.00 \pm 7.89$, respectively (mean \pm S.E.M., $n=6,5 ;{ }^{*} P=0.005$, two-tailed $t$-test).

$$
\begin{array}{lllllllll}
L & E & A & R & N & I & N & G & \mathbf{Q} \\
\mathbf{2 1 2} & M & E & M & O & R & Y
\end{array}
$$


tisense-treated cultures than in sense controls (Fig. 1C; $P=0.005$, two-tailed $t$-test).

Immunoblots of unfractionated samples from naive and NMDA-treated cultures were counterstained for proteins that might reveal nonspecific (or unintended) effects of translational suppression. Levels of a presynaptic vesicular protein (synaptophysin), a postsynaptic glutamate receptor subunit (GluR1) and a lysosomal protease (cathepsin D) were assayed. The first two antigens provide markers for transmission, whereas cathepsin D (and synaptophysin) concentrations are known to be sensitive to perturbations of lysosomal proteases (specifically, the inhibition of the cysteine proteases cathepsin $\mathbf{L}$ and cathepsin $\mathrm{B}$; Bahr et al. 1994). As shown in Figure 1C, translational suppression of calpain 1 did not reliably affect the concentrations of these proteins.

Baseline field EPSPs collected from control and experimental slices are shown in Figure 2 . There were no evident between-group differences in the sizes or waveforms of the responses. The average amplitude of baseline field EPSPs was $-0.98 \pm 0.12 \mathrm{mV}$ (mean \pm s.E.M.) in the antisense slices and $-0.91 \pm 0.06 \mathrm{mV}$ in the sense-treated group. The half-widths of synaptic responses in the two groups were also similar: $9.36 \pm 0.56 \mathrm{msec}$ (antisense) and $8.39 \pm 0.73 \mathrm{msec}$ (sense). The stimulation currents used to elicit field EPSPs varied substantially between slices within a group, but there was not a systematic difference between the two groups $(6.52 \pm 0.57 \mu \mathrm{A}$ antisense, $9.04 \pm 1.23 \mu \mathrm{A}$ sense; $P=0.06$ ). Moreover, there were no correlations between the strength of stimulation used to evoke baseline responses and the percent LTP obtained (not shown). In all, then, translational suppression did not appear to cause appreciable changes in baseline synaptic physiology.

Field EPSPs collected after $\theta$-burst stimulation revealed important similarities and differences between control slices and those with reduced calpain 1 levels. The effects of $\theta$-burst stimulation on slices from the two treatment groups are summarized in Figure 2. Both sense- and antisensetreated slices exhibited an immediate and substantial potentiation of the slope and amplitude of the field EPSP. As reflected in the field EPSP amplitude, the magnitude of this potentiation effect varied considerably across slices but was not reliably different for the two groups: $38.4 \pm 6.6 \%$ of baseline at $1 \mathrm{~min}$ post $\theta$ for the antisense slices $(n=12$, mean \pm S.E.M. ) and $44.6 \pm 7.5 \%$ for the sense slices
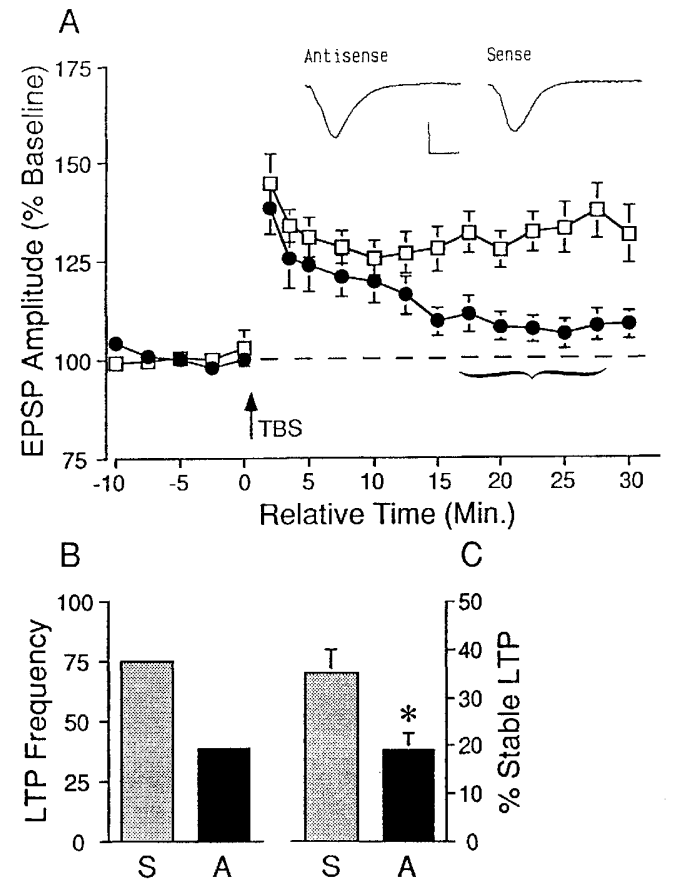

Figure 2: The effects of translational suppression of calpain 1 on LTP. Following the 5-day treatment period, hippocampal explants were transferred to an interface recording chamber where they were tested for the ability to express LTP. (A) Time plot of the average response before and after $\theta$-burst stimulation in sense- $(\square)$ and antisense-treated (O) slices; values are expressed as a percentage of baseline field EPSP amplitude. Field EPSPS elicited in the stratum radiatum of CA1 were comparably enhanced in the two groups of slices immediately following LTP-inducing stimulation. One minute after LTP induction, field EPSPs collected from antisense slices were on average $138.4 \pm 6.6 \%(n=12)$ of baseline, whereas those recorded from sense slices averaged $144.6 \pm 7.5 \% \quad(n=10 ; P=0.542$, two-tailed $t$-test $)$. At later time points, beginning at $\sim 10 \mathrm{~min}$, antisense slices exhibited markedly less LTP relative to controls. Although it had time-dependent effects on potentiated responses, antisense treatment did not appear to have adverse effects on baseline responses (inset waveforms; $x=10 \mathrm{msec}, y=0.5 \mathrm{mV}$ ). Heterosynaptic effects of $\theta$-burst stimlulation were minimal and, when present, short-lived; no between-group differences in the stability of control pathways were found (not shown). (B) The relative frequency of occurrence of LTP in sense- and antisense-treated cultures. When defined as $a \geqslant 10 \%$ enhancement $17-28 \mathrm{~min}$ after $\theta$-burst stimulation (bracket in A), LTP was obtained in 9 of 12 sense-treated slices and in 5 of 13 slices treated with antisense oligonucleotides. As shown in C, the average magnitude of LTP in slices exhibiting $\geqslant 10 \%$ potentiation was significantly reduced in the antisense group relative to controls $(19.2 \pm 3.6 \%$ vs. $35.1 \pm 4.1 \%$, respectively, mean \pm S.E.M.; $* P=0.037$, two-tailed $t$-test).

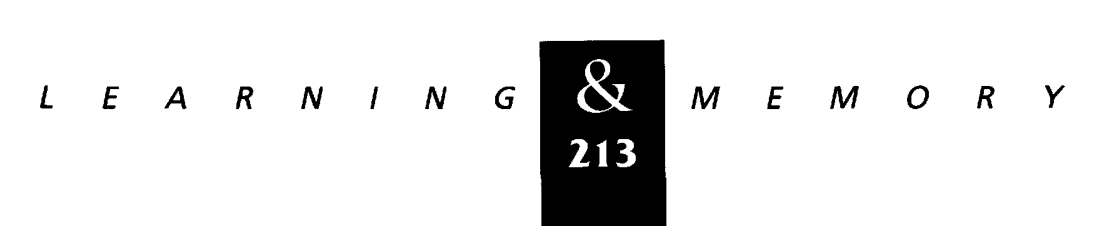


$(n=10)$. One slice in the antisense group and two slices in the sense group failed to show this shortterm potentiation (STP) effect and were excluded from the analysis; heterosynaptic effects of the theta-burst stimulation in this study were rare and, importantly, not persistent (not shown). In that STP and LTP have a shared reliance on NMDA receptor currents and elevations in postsynaptic calcium, it appears, then, that these processes required for LTP induction were similarly engaged in the two groups and were not compromised by suppression of calpain 1 . However, beginning $\sim 10$ min after $\theta$-burst stimulation, large differences between the LTP profiles of control and experimental slices became evident; the mean percent potentiation in the sense slices stabilized at $\sim 30 \%$ above baseline, whereas that in the antisense treatment group continued to decay to near $10 \%$ (Fig. $2 A)$. Over a stable post $-\theta$ window (17-28 min.), both the incidence (Fig. 2B) and the average magnitude of LTP were substantially reduced in antisense compared with sense slices. When defined as $a \geqslant 10 \%$ enhancement of field EPSP amplitude during this period, LTP was observed in $38.5 \%$ of antisense-treated slices (compared with a $75 \%$ occurrence in the sense group), with an average magnitude of $19.2 \pm 3.6 \%$ (mean \pm s.E.M.). This magnitude is considerably lower than the mean percent LTP found in sense-treated slices (35.1 $4.1 \%$; Fig. 2C); the difference was found to be statistically significant $(P=0.037$, two-tailed $t$-test).

\section{Discussion}

Translational suppression and organotypic culture techniques were combined to show that reduction of calpain 1 levels results in decreases in the incidence and magnitude of LTP induced by $\theta$-burst stimulation. Owing to paradigmatic advantages of the system used (e.g., antisense specificity), the present experiments constitute some of the most compelling evidence that calpain-mediated proteolysis is an essential step in the production of LTP. However, the methods used also present unique, possibly limiting, factors that must be considered in evaluation of the data gathered, these being the relative maturity of tissue in organotypic culture in relation to the timing of a manipulation, the nonselective effects of translational suppression of calpain 1 , and the adequacy of activity assays in determining the extent to which translational suppression reduced the levels of the protease in situ.

The results described are not likely to have been attributable to perturbations of developmental processes. The cultured slices were prepared from animals near the end of the second postnatal week and then maintained for $\mathbf{1 0}$ days before the start of the experiments. These procedures result in slices that express a wide range of adult physiological and anatomical characteristics (Stoppini et al. 1991; Vanderklish et al. 1992; Buchs et al. 1993; Muller et al. 1993) as well as levels of synaptic marker proteins that are constant for several weeks (Bahr 1995). Perhaps most importantly, a high synaptic density is reestablished after explantation at time points that precede our schedule of oligonucleotide delivery (Buchs et al. 1993; Muller et al. 1993). It is thus unlikely that reduction of LTP frequency and magnitude in the explants was attributable to an interruption by calpain 1 suppression of processes underlying the development of adult-like synaptic characteristics in culture.

In addition to timing, nonspecific effects of the manipulation on preparation viability are also an issue. Translational suppression was selective for calpain 1 inasmuch as changes were not seen in synaptophysin and cathepsin D, two proteins whose concentrations are rapidly and profoundly affected by drugs that inhibit lysosomal proteases (Bahr et al. 1994). Moreover, in that a minimal number of mismatches in the target complimentarity of antisense oligonucleotides has been shown to render them ineffective (Milligan et al. 1993), it can be assumed that calpain 2 (with 9 of 21 possible mismatches) was largely unaffected by the manipulation-though we do not have data to this end. Finally, translational suppression had no appreciable effect on baseline synaptic responses, as would have occurred if reductions in calpain 1 caused generalized changes in the physiology or chemistry of the slices.

As mentioned earlier, difficulties in obtaining reliable Western blot measurements of calpain 1 prompted us to utilize activity assays to guage the relative levels of the protease in antisense- and sense-treated cultures. Potential disadvantages of the approach are anitsense-induced changes in the abililty to purify calpain 1 and nonspecificity. The possibility that the effects of translational suppression on calpain 1 activity levels could be ascribed to altered extractability of the protease, rather than a specific retardation of its translation, seems

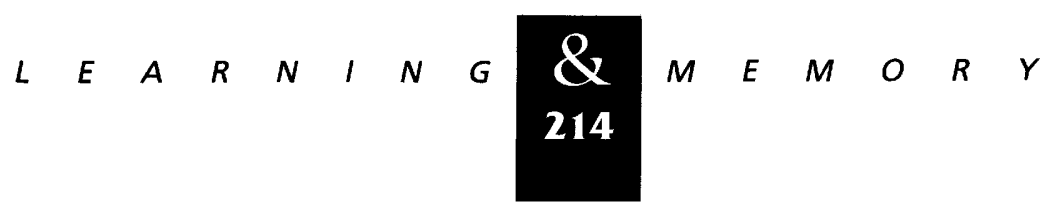


unlikely. First, it is difficult to imagine how such an effect would arise differentially from antisense rather that sense oligos, or from a mechanism other than nonspecific ionic interactions between the oligos, calpain, and membrane docking sites for the protease. If this were actually the case, then effects on extractability should be obtained with very brief treatment of the cultures with the DNA. However, in our hands, 5 days of continuous exposure to antisense oligos are typically needed to achieve robust suppression of calpain 1 activity, with very little or no reductions evident after 1 or 2 days. Furthermore, in initial efforts to characterize the applicability of the ${ }^{14} \mathrm{C}$-caseinolytic assay to measurements of calpain activity in organotypic cultures, we were able to detect differences in the relative levels of calpain activity in whole homogenates of antisense- versus sense-treated slices. Calcium-dependent proteolysis in these samples was, however, only fractionally greater than background ${ }^{14} \mathrm{C}$-caseinolytic activity, which lended to high variability in estimates of calpain 1 suppression and, in combination with the variability associated with LTP expression in culture, precluded a direct correlation between the degree of reduction of calpain 1 and the magnitude of potentiation. For this reason, we opted to increase the signal and reduce the noise of the assay by partially purifying calpain 1 from groups of slices. Purification, in conjunction with micromolar concentrations of calcium in the assay, also increased the likelihood that the only protease contributing to the calcium-dependent ${ }^{14} \mathrm{C}$-caseinolytic signal was calpain 1 (a conclusion that is also supported by the fact that this activity was completely inhibited by calpain inhibitor 1 ). If such specificity was not afforded by the assay, then the results presented here would represent an underestimate of the level of calpain 1 depletion. In any event, the fact that we observed similar reductions with antisense treatment in the levels of a calpain-specific spectrin breakdown product in homogenates of cultures treated with NMDA suggests that our activity assays were a reliable index of calpain 1 suppression.

The lack of an interaction between translational suppression of calpain 1 and baseline synaptic responses suggests that calpain activation at a level found in control slices is not required for normal synaptic transmission. This is not unexpected given that the calcium concentration required to activate the protease (1-5 $\mu \mathrm{m}$; Saido et al. 1994) is well above that found postsynaptically under resting conditions or that which occurs with typical excitatory responses. However, as noted, micromolar levels of calcium are reached during periods of intense, repetitive afferent activity (Guthrie et al. 1991; Muller and Connor 1991; Petrozzino et al. 1995), and such activity is associated with the occurrence in dendrites of proteolytic fragments of spectrin that are characteristic of calpain activation (Vanderklish et al. 1995). The present findings, in concert with previous work, thus point to the conclusion that the calpain response is a rarely used mechanism of hippocampal neurons that has special significance to the development of LTP.

The nature of the contribution made by the protease to LTP remains to be determined, but it is noteworthy that the magnitude of potentiation during the first few minutes after induction was not significantly different in the experimental slices. This observation is in accord with data obtained with pharmacological inhibitors of the protease (del Cerro et al. 1990; Denny et al. 1990) and indicates that the mechanisms responsible for induction and early expression of potentiation remain more or less intact in the face of reduced levels of calpain 1. It might be argued that although the primary triggers of LTP appear to be uncompromised by translational suppression, the effects observed may still be due to an increase in the threshold for induction. This would be compatible with the data if one assumes that LTP induction involves the initiation of processes that give rise to immediate enhancement of synaptic responses (e.g., kinase activation), and other processes such as calcium-dependent proteolysis that might be involved in reconfiguring the synapse for the stable expression of potentiation. Indeed, what is clearly impaired by suppression of calpain 1 is the stabilization of LTP, and the results may be attributable to an increase in the threshold of changes subserving stability.

Multiple types of evidence point to an AMPA receptor locus of LTP expression and a dependence of LTP stability on changes in molecules supporting cell adhesion (i.e., integrins and NCAMs; Staubli et al. 1991; Xiao et al. 1991; Luthi et al. 1994; Ronn et al. 1995). Added to this is the demonstration that AMPA receptors are sensitive to changes in the membrane/cytoskeletal environment in which they are embedded (Terramani et al. 1988; Massicotte et al. 1991; Hall et al. 1992). In this context, the present observations are consistent with a view of LTP that regards (1) expres-

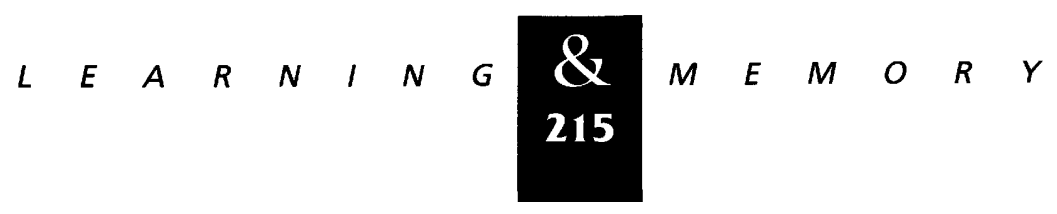


sion as a receptor state imparted by synaptic structure and (2) calpain-mediated proteolysis as a mechanism permitting lasting reorganization of this structure. A role of this type for the protease seems reasonable given that its preferred substrates include cytoskeletal (Siman et al. 1984; Croall and DeMartino 1991; Dosemeci and Reese 1995) and adhesion (Covault et al. 1991; Sheppard et al. 1991 ) proteins known to be concentrated in the synaptic zone.

\section{Acknowledgments}

This work was supported by grants from the National Institute on Aging (AG00538) and the Air Force Office of Scientific Research (95-I-0304) to G.L.

The publication costs of this article were defrayed in part by payment of page charges. This article must therefore be hereby marked "advertisement" in accordance with 18 USC section 1734 solely to indicate this fact.

\section{References}

Aoki, K., S. Imajoh, S. Ohno, Y. Emori, M. Koike, G. Kosaki, and K. Suzuki. 1986. Complete amino acid sequence of the large subunit of the low-Ca ${ }^{2+}$-requiring form of human $\mathrm{Ca}^{2+}$-activated neutral protease ( $\mu$ CANP) deduced from its cDNA sequence. FEBS Lett. 205: 313-317.

Bahr, B.A. 1995. Long-term hippocampal slices: A model system for investigating synaptic mechanisms and pathological processes. /. Neurosci. Res. 42: 294-305.

Bahr, B.A., B. Abai, C.M. Gall, P.W. Vanderklish, K.B. Hoffman, and G. Lynch. 1994. Induction of $\beta$-Amyloid-containing polypeptides in hippocampus: Evidence for a concomitant loss of synaptic proteins and interactions with an excitotoxin. Exp. Neurol. 129: 81-94.

Bahr, B.A., S. Tiriveedhi, G.Y. Park, and G. Lynch. 1995. Induction of calpain-mediated spectrin fragments by pathogenic treatments in long-term hippocampal slices. J. Pharmacol. Exp. Ther. 273: 902-908.

Bednarski, E., P. Vanderklish, C. Gall, T.C. Saido, B.A. Bahr, and G. Lynch. 1995. Translational suppression of calpain I reduces NMDA-induced spectrin proteolysis and pathophysiology in cultured hippocampal slices. Brain Res. 694: $147-157$.

Bliss, T.V.P. and G.L. Collingridge. 1993. A synaptic model of memory: Long-term potentiation in the hippocampus. Nature 361: 31-39.

Bliss, T.V.P. and T. Lomo. 1973. Long-lasting potentiation of synaptic transmission in the dentate area of the anaesthetized rabbit following stimulation of the perforant path. I. Physiol. 232: 331-356.

Bradford, M. 1976. A rapid and sensitive method for the detection and quantification of microgram quantities of protein utilizing the principle of protein-dye binding. Anal. Biochem. 421: 167-172.

Buchs, P.-A., L. Stoppini, and D. Muller. 1993. Structural modifications associated with synaptic development in area CA1 of rat hippocampal organotypic cultures. Dev. Brain Res. 71: 81-91.

Carlin, R.K., D.C. Bartelt, and P. Siekevitz. 1983. Identification of fodrin as a major calmodulin-binding protein in postsynaptic density preparations. /. Cell Biol. 96: $443-448$.

Covault, J., Q.Y. Lui, and S. el-Deeb. 1991.

Calcium-activated proteolysis of intracellular domains in the cell adhesion molecules NCAM and N-cadherin. Mol. Brain Res. 11: 11-16.

Croall, D.E. and G.N. DeMartino. 1991. Calcium-activated neutral protease (calpain) system: Structure, function, and regulation. Physiol. Rev. 71: 813-847.

del Cerro, S., J. Larson, M.W. Oliver, and G. Lynch. 1990 Development of hippocampal long-term potentiation is reduced by recently introduced calpain inhibitors. Brain Res. 530: 91-95.

Denny, J.B., J. Polan-Curtain, A. Ghuman, M.J. Wayner, and D.L. Armstrong. 1990. Calpain inhibitors block long-term potentiation. Brain Res. 534: 317-320.

Dosemeci, A. and T.S. Reese. 1995. Effect of calpain on the composition and structure of postsynaptic densities. Synapse 20: 91-97.

Emori, Y., H. Kawasaki, H. Sugihara, S. Imajoh, S. Kawashima, and S. Suzuki. 1986. Isolation and sequence analysis of cDNA clones for the large subunits of two isozymes of rabbit calcium-dependent protease. J. Biol. Chem. 261: 9465-9471.

Fukuda, T., E. Adachi, S. Kawashima, I. Yoshiya, and P.H. Hashimoto. 1990. Immunohistochemical distribution of calcium-activated neutral proteinases and endogenous CANP inhibitor in the rat hippocampus. I. Comp. Neurol. 302: 100-109.

Guthrie, P.B., S. Menahem, and S.B. Kater. 1991. Independent regulation of calcium revealed by imaging dendritic spines. Nature 354: 76-79.

Hall, R., M. Kessler, and G. Lynch. 1992. Evidence that high- and low-affinity

DL-alpha-amino-3-hydroxy-5-methylisoxazole-4-propionic acid (AMPA) binding sites reflect membrane-dependent states of a single receptor. I. Neurochem. 59: 1997-2004.

Ivy, G.O., P. Seubert, M. Baudry, and G. Lynch. 1988. Presence of brain spectrin in dendrites of mammalian brain: Technical factors involved in immunocytochemical detection. Synapse 2: 329-333.

Larson, J. and G. Lynch. 1986. Induction of synaptic

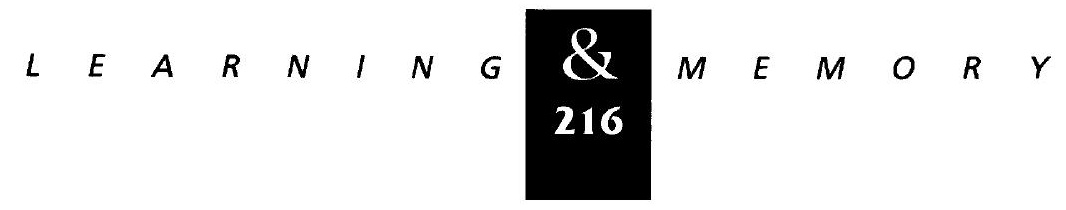


potentiation in hippocampus by patterned stimulation involves two events. Science 232: 985-988.

Luthi, A., J.P. Laurent, A. Figurov, D. Muller, and $M$. Shachner. 1994. Hippocampal long-term potentiation and neural cell adhesion molecules L1 and NCAM. Nature 372: 777-779.

Lynch, G., B.A. Bahr, and P.W. Vanderklish. 1991a. Induction and stabilization of long-term potentiation. In Clutamate, cell death and memory (ed. P. Ascher, D.W. Choi, and Y. Christen), pp. 45-60. Springer-Verlag, Berlin, Germany.

Lynch, G., J. Larson, U. Staubli, R. Granger. 1991b. Relating variants of synaptic potentiation to different types of memory operations in hippocampus and related structures In Memory: Organization and locus of change (ed. L.R. Squire, N.M. Weinberger, G. Lynch, and J.L. McGaugh), pp. 339-363. Oxford University Press, New York, NY.

Massicotte, G., P. Vanderklish, G. Lynch, and M. Baudry. 1991. Modulation of DL- $\alpha$-amino-3-hydroxy-5methylisoxazole proprionic acid/quisqualate receptors by phospholipase $\mathrm{A}_{2}$ : A necessary step in long-term potentiation? Proc. Natl. Acad. Sci. 88: 1893-1897.

Milligan, J.F., M.D. Matteucci, and J.C. Martin. 1993. Current concepts in antisense drug design. J. Med. Chem. 36: 1923-1937.

Muller, D., P.-A. Buchs, and L. Stoppini. 1993. Time course of synaptic development in hippocampal organotypic cultures. Dev. Brain Res. 71: 93-100.

Muller, D., I. Molinari, L. Soldati, G. Bianchi. 1995. A genetic deficiency in calpastatin and isovalerylcarnitine treatment is associated with enhanced hippocampal long-term potentiation. Synapse 19: 37-45.

Muller, W.A. and J.A. Connor. 1991. Dendritic spines as individual neuronal compartments for synaptic $\mathrm{Ca}^{2+}$ responses. Nature 354: 73-76.

Perlmutter, L.S., C. Gall, M. Baudry, and G. Lynch. 1990. Distribution of calcium-activated protease calpain in rat brain. J. Comp. Neurol. 296: 269-276.

Peterson, C., P. Vanderklish, P. Seubert, C. Cotman, and G. Lynch. 1991. Increased spectrin proteolysis in fibroblasts from aged and Alzheimer donors. Neurosci. Lett. 121: 239-243.

Petrozzino, J.J., L.D. Pozzo Miller, and J.A. Connor. 1995. Micromolar $\mathrm{Ca}^{2+}$ transients in dendritic spines of hippocampal pyramidal neurons in brain slice. Neuron 14: 1223-1231.

Roberts-Lewis, J.M., M.J. Savage, V.R. Marcy, L.R. Pinsker, and R. Siman. 1994. Immunolocalization of calpain I-mediated spectrin degradation to vulnerable neurons in the ischemic gerbil brain. J. Neurosci. 14: 3934-3944.
Ronn, L.C., E. Bock, D. Linnemann, and H. Jahnsen. 1995. NCAM-antibodies modulate induction of long-term potentiation in rat hippocampal CA1. Brain Res. 677: 145-151.

Saido, T.C., M. Yokota, S. Nagao, I. Yamaura, E. Tani, T. Tsuchiya, K. Suzuki, S. Kawashima. 1993. Spatial resolution of fodrin proteolysis in postischemic brain. J. Biol. Chem. 268: 25239-25243.

Saido, T.C., H. Sorimachi, and K. Suzuki. 1994. Calpain: New perspectives in molecular diversity and physiological-pathophysiological involvement. FASEB J. 8: 814-822.

Sheppard, A., J. Wu, U. Rutishauser, and G. Lynch. 1991. Proteolytic modification of neural cell adhesion molecule (N-CAM) by the intracellular proteinase calpain. Biochem. Biophys. Acta 1076: 156-160.

Siman, R., M. Baudry, and G. Lynch. 1984. Brain fodrin: Substrate for the endogenous calcium-activated protease, calpain 1. Proc. Natl. Acad. Sci. 81: 3276-3280.

Siman, R., C. Gall, L.S. Perlmutter, and G. Lynch. 1985. Distribution of calpain I, an enzyme associated with degenerative activity, in rat brain. Brain Res. 347: 399-403.

Staubli, U., J. Larson, O. Thibault, M. Baudry, and G. Lynch. 1988. Chronic administration of a thiol-proteinase inhibitor blocks long-term potentiation of synaptic responses. Brain Res. 444: 153-158.

Staubli, U., P. Vanderklish, and G. Lynch. 1991. An inhibitor of integrin receptors blocks long-term potentiation. Behav. Neurol. Biol. 53: 1-5.

Stoppini, L., P.-A. Buchs, and D. Muller. 1991. A simple method for organotypic cultures of nervous tissue. /. Neurosci. Methods 37: 173-182.

Terramani, T., M. Kessler, G. Lynch, and M. Baudry. 1988. Effects of thiol-reagents on

$\left[{ }^{3} \mathrm{H}\right]$ alpha-amino-3-hydroxy-5-methylisoxazole-4-propionic acid binding to rat telencephalic membranes. $\mathrm{Mol}$. Pharmacol. 34: 117-123.

Teyler, T.J. and P. DiScenna. 1984. Long-term potentiation as a candidate mnemonic device. Brain Res. Rev. 7: 15-28.

Vanderklish, P., R. Neve, B.A. Bahr, A. Arai, M. Hennegriff, J. Larson, and G. Lynch. 1992. Translational suppression of a glutamate receptor subunit impairs long-term potentiation. Synapse 12: 333-337.

Vanderklish, P., T.C. Saido, C. Gall, A. Arai, and G. Lynch. 1995. Proteolysis of spectrin by calpain accompanies theta-burst stimulation in cultured hippocampal slices. Mol. Brain Res. 32: 25-35.

Xiao, P., B.A. Bahr, U. Staubli, P.W. Vanderklish, and G. Lynch. 1991. Evidence that matrix recognition contributes to stabilization but not induction of LTP. NeuroReport 2: 461-464.

Received May 31, 1996; accepted in revised form August 28, 1996.

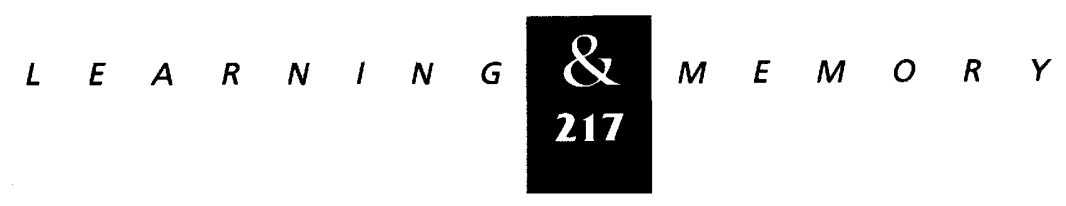




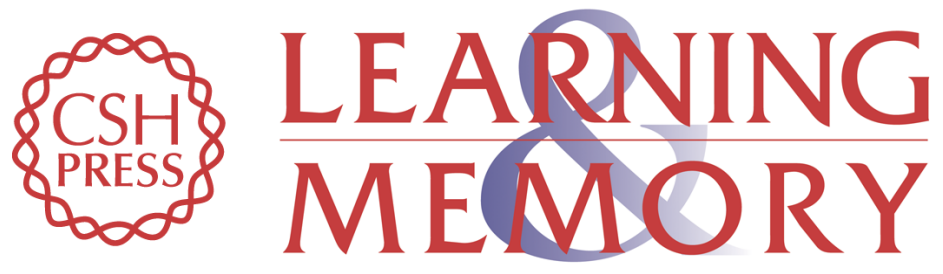

\section{Translational suppression of calpain blocks long-term potentiation.}

P Vanderklish, E Bednarski and G Lynch

Learn. Mem. 1996, 3:

References This article cites 45 articles, 8 of which can be accessed free at:

http://learnmem.cshlp.org/content/3/2-3/209.full.html\#ref-list-1

License

Email Alerting Receive free email alerts when new articles cite this article - sign up in the box at the Service top right corner of the article or click here. 